\title{
ОСОБЕННОСТИ ИНФЛЯЦИИ И АНТИИНФЛЯЦИОННОЙ ПОЛИТИКИ ГОСУДАРСТВА В РЫНОЧНЫХ УСЛОВИЯХ
}

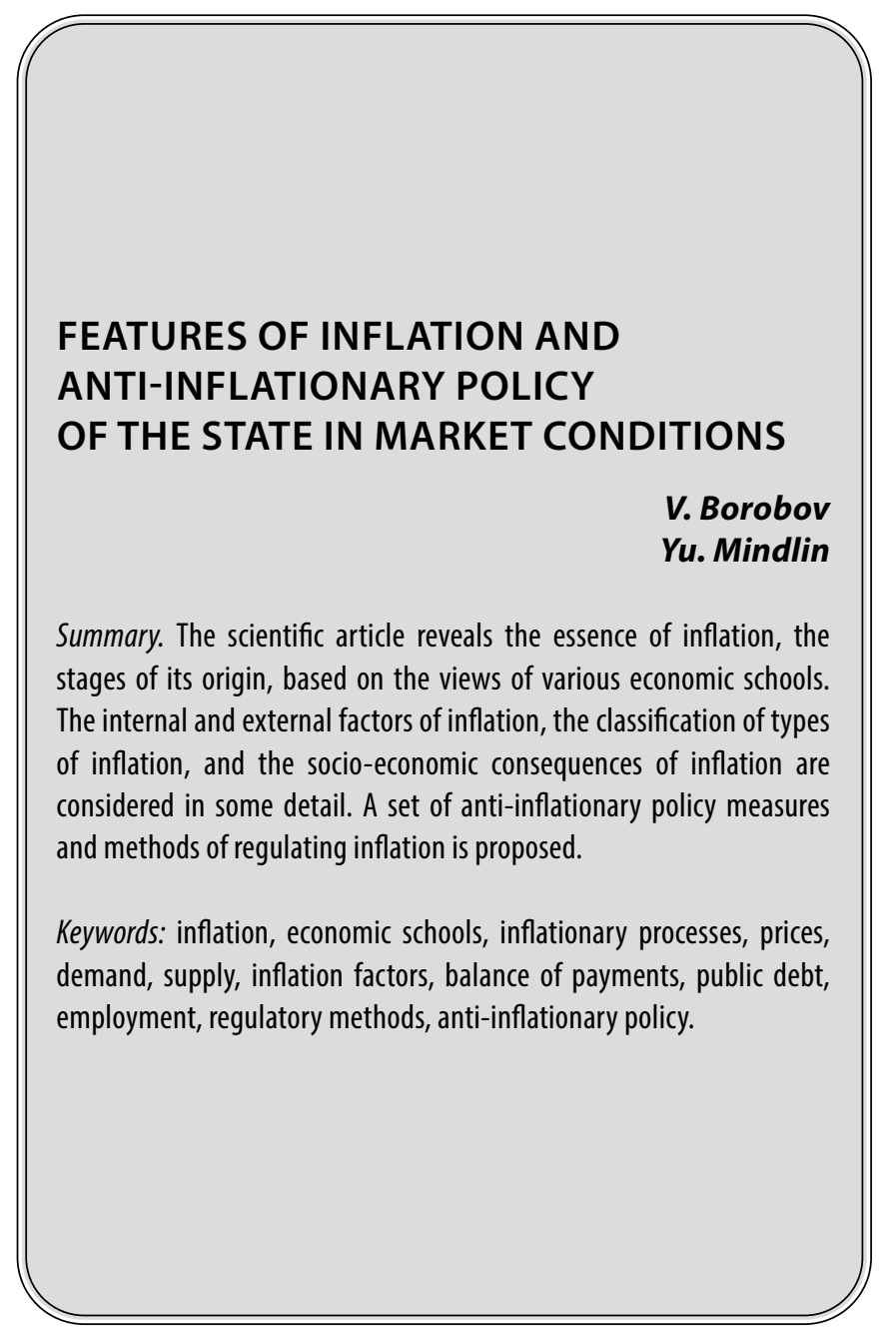

B данной статье рассматривается понятие одного из самых противоречивых экономических явлений - инфляция, а также анализируется её влияние на банковский сектор.

Инфляция возникла ещё до распространения бумажных денег и уже тогда имела сильное воздействие на экономику. Сам термин «инфляция» впервые был введён американским экономистом А. Делмаром в 1864году в период гражданской войны в США, и именно с того времени начинается тщательное её изучение.

За это время различными экономическими школами было предложено множество интересных концепций происхождения, влияния инфляции, а также мер по борьбе с ней.
Боробов Василий Николаевич

Д.э.н., профессор, Московская государственная академия ветеринарной медицины и биотехнологий МВА имени К.И. Скрябина; Финансовый университет при Правительстве Российской Федерации vborobov@mail.ru

Миндлин Юрий Борисович

К.э.н., доцент, Московская государственная академия ветеринарной медицины и биотехнологийМВА имени К.И. Скрябина mindliny@mail.ru

Аннотация. В научной статье раскрывается сущность инфляции, этапы её происхождения, основываясь на взгляды различных экономических школ. Довольно подробно рассматриваются внутренние и внешние факторы инфляции, классификация видов инфляции, социально-экономические последствия инфляции. Предлагается комплекс мер антиинфляционной политики, методов регулирования инфляции.

Ключевые слова: инфляция, экономические школы, инфляционные процессы, цены, спрос, предложение, факторы инфляции, платёжный баланс, государственный долг, занятость населения, методы регулирования, антиинфляционная политика.

Проблема изучения инфляции продолжает оставаться актуальной в наше время, поскольку данное явление представляет собой неотъемлемую часть любой рыночной экономики и в той или иной степени присуще любой стране. Инфляция, характеризующаяся высокими темпами роста, может привести страну к глубокому экономическому и политическому кризису, либо привести к краху всей её экономики. Она является многофакторным явлением и затрагивает практически все сферы жизни общества, обостряя социальные противоречия, способствуя росту теневого сектора экономики. Поэтому государству и прочим субъектам экономики важно учитывать инфляционные процессы в своей деятельности, а также проводить эффективную политику, чтобы держать значение инфляции в определённых границах с целью предотвращения её отрицательного влияния 
на хозяйственную и социальную жизнь страны, а также возможного извлечения выгоды из данной ситуации.

Целью написания научной статьи является изучение инфляционных процессов, происходящих в нашей стране в данный момент, а также определение её влияния на банковский сектор РФ и его функционирование.

При написании статьи были использованы аналитический метод, а также изучение публикаций и статей по данной теме.

Такое экономическое явление как инфляция напрямую связано с возникновением и обращением денег, а значит, появилось очень давно.

Исторически самым первым типом была именно бумажно-денежная инфляция, однако в истории встречаются также примеры монетарно-денежной инфляции.

К.Р. Макконнелл и С.Л.Брю приводят довольно наглядное понятие инфляции: «Слишком много денег охотится за слишком малым количеством товаров».

Сам термин «инфляция» (от лат. influtio- «вздутие») впервые был введён американским экономистом А. Делмаром в 1864 году, в период Гражданской войны в США (1861-1865). [2]

Впоследствии это понятие тщательно исследовалось представителями различных экономических течений, вследствие чего выделились три основополагающих теории инфляции, по-разному определяющих её сущность и природу происхождения. Так, сторонники кейнсианства убеждены, что наиболее значительным фактором роста цен выступает чрезмерный спрос на отдельные группы товаров на рынках, что порождает избыточный совокупный спрос. Наиболее известные теоретики: Дж.М. Кейнс, Б. Хансен.

По утверждению сторонников монетаризма (М. Фридмена и других), причина инфляционного лага между деньгами и товарами сводится к чрезмерному увеличению денежной массы. Они руководствуются уравнением обмена $\mathrm{MV}=\mathrm{PQ}$, которое схематически отражает взаимосвязь таких показателей, как денежная масса (M), уровень цен (P), скорость обращения денежной массы (V) и её количеством в экономике(Q). [4]

Третья теория - теория чрезмерных издержек (представители: Дж.М. Кейнс, У. Торн, Р. Куэн)- состоит в обосновании природы инфляции производственными издержками, которые обусловлены повышением заработной платы и цен на сырьё. Авторы полагают, что определяющим является рост заработной платы, способствующий повыше- нию товарных цен, что, в свою очередь, влияет на последующее повышение оплаты труда. Это явление экономисты на Западе (П. Самуэльсон, Дж. Гэлбрейт и др.) обозначили как инфляционная спираль «заработная плата — цены». [3]

Таким образом, монетаристы видят причины инфляции в избыточном количестве денежных средств, находящихся в обращении, т.е. считают исключительно денежным феноменом. Сторонники отличных от их теорий основными причинами считают структурные несовершенства экономической сферы общества.

В полной мере инфляцию можно охарактеризовать как обесценение денежных средств, уменьшение их покупательной способности вследствие роста цен, дефицита товаров и услуг, а также снижением их качества. [2]

\section{ГАавные признаки инф^яционного роста чен: $А$ ите^ьность, массовость, непрерывность}

В основе описываемого явления - диспропорциональность различных экономических сфер: потребления и накопления, спроса и предложения; государственными расходами и доходами; потребностью в денежных средства и количеством денежной массы, находящейся в обращении. Инфляцию вызывают различные факторы: внутренние и внешние. Ко внутренним факторам относят неденежные и денежные. Поскольку на инфляцию влияет огромное множество различных факторов, ниже перечислены лишь некоторые из них. [3]

К факторам денежного характера относят:

- дефицит государственного бюджета;

- дисбаланс финансовой сферы государства, когда Центральный банк вынужден осуществить дополнительную эмиссию банкнот для ликвидации дефицита денежных средств, а коммерческие банки - увеличить выдачи кредитов в наличной или безналичной форме; следствием данного увеличения денежной массы является её обесценение;

- темпы роста доходов населения превышают темпы роста товарной массы, при этом эффект для экономики может быть как отрицательным, так и положительным, поскольку это может привести и к расширению производства;

- увеличение скорости оборота денег;

- рост государственного долга;

- меры правительства по поддержанию курса нац. валюты, ограничение его от колебаний и т.д.

Факторы не денежного характера:

- структурные диспропорции в общественном воспроизводстве, финансовая несбалансированность, которая имеет две формы. Первая 
форма финансовой несбалансированности материально-вещественного и стоимостного фонда потребления, которая является следствием несоответствия структуры спроса предложению товаров и услуг. Вследствие несбалансированности бюджета государства возникает потребность в дополнительной эмиссии денег. Вторая форма - товарно-денежная несбалансированность фонда потребления- приводит к невыполнению кассового плана и необходимости дополнительной денежной эмиссии. Это результат нарушения баланса материально-вещественной и стоимостной структуры общественного продукта в целом.

- монополизация экономики;

- милитаризация экономики;

- несбалансированность инвестиций;

затратный механизм хозяйствования;

гос. эк., фин. и налоговая политика и т.д.

Внешние факторы:

- мировые структурные кризисы (сырьевой, энергетический, валютный);

- инфляция, «импортируемая» из других стран;

- нелегальный экспорт золота, валюты;

- большой размер государственного долга и отвлечение значительных бюджетных средств на его обслуживание (порог экономической безопасности по обслуживанию внешнего долга составляет не более $25 \%$ бюджетных расходов);

- отрицательное сальдо платёжного баланса;

- увеличение объемов иностранной валюты и её покупка Центробанком, что приводит к дополнительной эмиссии национальной валюты и другие факторы.[2]

На основании вышеизложенного можно сделать вывод, что инфляция - это сложное явление, на которое влияет множество факторов. При этом следует отметить, что перечень факторов и степень их влияния в стране определяется её отличительными особенностями и социально-экономическим развитием.

Существует множество классификаций понятия инфляции, в зависимости от признака, взятого за основу.

Одна из основных классификаций связана с рассмотренными выше теориями инфляции и основывается на том, факторы какой группы (внешние или внутренние, денежные или не денежные) оказывают на неё преобладающее воздействие. В зависимости от этого выделяют инфляцию спроса и инфляцию издержек, о которых было сказано в первом пункте.

По формам проявления инфляция бывает открытой, которая выявляется в увеличении цен на товары и при- суща условиям свободного ценообразования, особенно экономики рыночного, и подавленной (скрытой), при которой рост цен на товары и услуги может быть не сильно заметен, а дефицит предложения может быть спровоцирован обесцениванием денежной массы.

В зависимости от темпов роста цен на рынке открытая инфляция бывает:

- ползучая (умеренная) (не более 10\% в год). Этот вид инфляции присущ странам с развитой экономической системой. Считается, что такой тип инфляции не оказывает существенного влияния на состояние в котором находится экономика данной страны, а относительно невысокий (3\%) её темп может быть даже использован для стимулирования производства.

- галопирующая (от 10 до 200\% в год). Характерная для стран с переходной экономикой. Оказывает негативное влияние на всю хозяйственную систему страны.

- гиперинфляция (более 50\% в месяц, переводя в исчисление по году, около 1000\%). Однако данные темпы являются условными поскольку нужно брать во внимание экономику разных стран. Качественно принято считать, что границей гиперинфляции является состояние национального хозяйства, когда денежные единицы прекращают выполнять свои функционал, встречается общественное «бегство» от денежной массы, деструкция финансово-кредитной системы. Такая инфляция разрушительно действует на экономику, является катализатором перехода к обмену по бартеру. [25]

По критерию уровня сбалансированности ценового роста выделяют сбалансированную и несбалансированную инфляцию. При сбалансированном инфляционном процессе ценообразование на разные категории товаров происходит не зависимо друг от друга (при увеличении цен происходит сохранение ценовых пропорций). Однако на самом деле это лишь теоретическая абстракция, поскольку в силу различной эластичности спроса по цене различных товаров их цены меняются по-разному. Более или менее сбалансированная инфляция не опасна для бизнеса. При несбалансированном типе инфляционных процессов, напротив, цены на товары подвержены постоянным изменениям по отношению друг к другу, хотя пропорции различны. [4]

Относительно степени предсказуемости выделяют ожидаемую инфляцию, которую можно предсказать загодя и составить прогнозы, которые будут отличаться достаточной степенью надежности и нередко может привести к непосредственным действиям правительства, и неожиданную, которая характеризуется внезап- 
ным ростом цен на рынке страны, что не может положительно сказываться на системе налогообложения и обращения денежной массы в данном государстве. В случае наличия инфляционных ожиданий у населения, при неожиданной инфляции, случается скачок роста цен, однако при их отсутствии возможен «эффект Пигу», т.е. стремительный упадок спроса у населения, связанный с ожиданиями на скорое снижение цен, и тогда из-за снижения спроса производитель вынужден уменьшать цену на производимый товар, и всё приходит к равновесию. [26]

Отдельно выделяют такое явление как стагфляция, которое характеризуется единовременным увеличением уровня цен в стране, сокращение объёмов производства и, как результат, повышению уровня безработных.

Основные социально- экономические последствия инфляции заключаются в:

1. Падении покупательной способности. Инфляционные процессы создают ситуацию, при которой большая часть денежной массы (населения, предприятий и государства) уменьшаются из-за разницы в номинальном и реальном доходах. Соответственно люди с фиксированным доходом наиболее подвержены негативному влиянию инфляции.

2. Перераспределении доходов и богатства. Таким образом, должники становятся богаче за счёт кредиторов, более того, положительный эффект сказывается и на правительстве, которое накапливает большой государственный долг, поскольку инфляционные процессы позволяют оплачивать долги деньгами, которые обладают более низкой покупательной способностью. В процессе инфляции происходит распределение средств благодаря тем, кто вкладывает денежные средства по фиксированной ранее договоренности - номинальной и долгосрочной, к примеру, процентная ставка за кредит или заработная плата, в пользу тех, кто отсрочивает платежи. Данное перераспределение усиливает неожиданность, и несбалансированность инфляции в целом. Кроме того, в период инфляции возрастает стоимость недвижимого имущества. Можно сделать вывод, что инфляция является катализатором разрыва между слоями населения с разным уровнем дохода, что усиливает противоречия в обществе. [15]

3. Материализации денежных средств. В процессе инфляции происходит рост цен на определенные категории товаров и услуг, которые пользуются большим спросом на рынке. Следовательно многие фирмы и предприятия пытаются стремительно материализовать свои обесценивающие- ся деньги в определенные запасы, что приводит к возрастанию инфляции спроса. [19]

4. Снижении интереса к долгосрочным целям. Складывается ситуация на рынке, когда рост вложенных средств, меньше, чем обесценивание этих вложенных денег. Выгодными могут быть только те инвестиции, рентабельность которых больше, чем темпы инфляционных процессов. Причем наибольший риск обесценивания наблюдается у более долгосрочных инвестиций.

5. Обесценении денежных сбережений.

6. Скрытой конфискация денежных средств и снижение реального процента. Путем взимания налогов происходит скрытая конфискация у населения и предприятий. Это обусловлено ростом номинального дохода, из-за которого налогоплательщики оказываются в группе с более высокой ставкой налогообложения, поскольку при подоходном обложении действует принцип прогрессивности, согласно которому, доходы, выходящие за определённые границы, облагаются сильнее.

7. Ухудшении управляемости экономики. Быстрая изменчивость цен посылает некорректные сигналы потребителю о состоянии рынка, из-за чего он не может принять оптимальное решение. Более того, у людей нет уверенности в доходах, они испытывают затруднения в прогнозировании затрат и прибыли, что приводит к снижению стимулов для предпринимательской деятельности и является катализатором экономической активности.

8. Влиянии на занятость населения. Это хорошо отражает выявленная А.Филлипсом в 1958 г. зависимость, которая прослеживается между уровнями безработицы и заработной платы. При дальнейшей модификации, произведенной представителями американской экономической школы П.Самуэльсоном и Р.Солоу, произошла замена уровня ставки заработной платы на темпы роста цен на категории товаров. Само понятие роста инфляции принято соотносить с высокой, хотя не во всех ситуациях полной занятостью населения и достаточно большим объемом национального производства. Это действует и в обратную сторону, так снижение инфляции в стране чаще всего совпадает со спадом производства и увеличением числа безработных граждан. Данная закономерность может быть определенном образом использована государством как составляющая антиинфляционной политики.

9. Более того, увеличивается спекуляция на ценах, ценных бумагах, процентных ставках и начинает быстро развиваться сектор теневой экономики, с целью избегания налогообложения. Также в пе- 
риод инфляции рубль теряет свою покупательную способность и происходит искажение ее реального курса по отношению к валютам других стран.

С другой стороны, инфляционные процессы могут иметь и положительное влияние на экономический сектор. Так, инфляционные процессы способствуют таким явлениям как оживление конъюнктуры и ускорению некоторых структур в экономике. Происходит увеличение деловой активности компаний, связанное с ожиданием роста цен на их продукцию и услуги; рост производства, простимулированный ростом денежной массы. А увеличение скорости оборота денег может положительно сказаться на работе банковской системы. Кроме того, происходит уменьшение долгов государства, в казну поступают доходы от налоговых сборов. Также в ситуации, когда курс рубля заметно падает возможно удешевление экспортных товаров, что может спровоцировать рост и расширение иностранных рынков по сбыту товаров. В этот же период происходит рост цен на импорт, что приводит к падению конкурентоспособности зарубежной продукции. [12]

Но, с другой стороны, помимо положительных моментов данного процесса, даже умеренная инфляция, которая составляет около 9-12\% в год, является угрозой для экономических систем разным стран, так как из-за неконтролируемых инфляционных ожиданий продавцов и потребителей может быть раскручена инфляционная спираль.

\section{Инф^льионное таргетирование \\ в России как наиболее актуальное направ^ение антиинф^яционной пОАИТИКИ}

Что касается инфляционных процессов, происходящих в России, можно сказать, что для России характерна открытая, несбалансированная, подкреплённая инфляция, темп роста которой по данным на 2019 г. равен 4\%. По состоянию за 2019 г. Россия является 8-й страной в мире по показателям инфляции.

В современное время инфляция стала хроническим явлением рыночной экономики, полностью избавиться от которого невозможно, поэтому задача государствапринимать меры для её сокращения и проводить адаптационную политику.

Существует множество методов регулирования инфляции.

К правовым средствам регулирования инфляции относят антикоррупционную деятельность, правовой мони- торинг, который следит за нормотворческим процессом и качеством нормативных актов, регулирующих финансовую, денежно-кредитную, бюджетно-налоговую и другие сферы, а также индексация. Также руководствуясь решениями, которые были приняты Советом Директоров банка России начиная с 27 июля 2020 г. Банк РФ установил ставку рефинансирования соответствующую 4,25\%, что было направлено на сдерживание инфляционных ожиданий. [22]

Так, согласно подходу сторонников монетаризма, для преодоления инфляции необходимо уменьшить долю наличных денег в обращении.

До 2014 г. политика Банка РФ считалась денежного таргетирования, которая позволяла держать под контролем динамику денежных агрегатов, особенно М2 и M3, а само денежное регулирование было направлено в основном на их «привязку» к динамике ВВП. Однако недостатком такой политики было то, что так называемое сжатие денежной массы способствовало прекращению роста цен, но и в то же время держало под контролем инвестиции и доходы, из-за чего затруднялось эффективное развитие рыночной экономики и экономический рост. [1] Кроме того, большинство методов монетарной политики воздействия на инфляционные процессы могут быть эффективными только в сбалансированной экономической среде, когда по цепочке производственных связей происходит изменение денежного предложения и затрагивается основная часть производственной отрасли, что на наблюдается в России. [13]

Согласно информации, указанной выше, инфляция в России является многофакторным явлением, поэтому следует брать во внимание не только монетарные факторы. Исследователями было выявлено, что отчётные данные за прошедший период времени не иллюстрирует сильной зависимости инфляционных процессов от увеличения расходов государственного бюджета и денег в предшествующие годы, инфляции было свойственно снижаться. [3]

По этой причине Банк России внес изменения в проводимую политику и осуществил переход к таргетированию в инфляционных процессах и активировал режим плавающего валютного курса национальной валюты, о чём было сказано в проекте «Основных направлений денежно-кредитной политики. По опыту других стран, этот процесс перехода занимает от 3 до 5 лет.

Под инфляционным таргетированием понимается такая разновидность денежно-кредитной политики, при которой происходит процесс выбора определенного показателя инфляции, которое будет представлено в качестве целевого ориентира и использование операционных инструментов ЦБ, наиболее часто встре- 
чающихся процентных ставок, что позволит достигнуть ожидаемый уровень инфляции, за который ответственны государственные структуры для достижения запланированного уровня инфляции.[11]

Центральный Банк выделяет следующие основные положения данной политики:

- поддержание ценовой стабильности — основная цель деятельности ЦБ РФ;

- ЦБ РФ устанавливает количественную цель выбранного показателя;

- за достижение целевого показателя несет ответственности ЦБ РФ;

- процентные ставки выступают в качестве основного инструмента денежно-кредитной политики;

- прогноз развития экономики, а также динамика показателей инфляции оказывают сильное влияние на принятие решений о выборе целевого значения;

- проводимая политика носит открытый характер.

Основной целью данной политики является желание снизить инфляционные ожидания всех субъектов хозяйствования в экономическом секторе благодаря укреплению доверия к проводимой властями и ЦБ политике и, как следствие, снижение реального уровня инфляции.

В настоящее время оптимальной таргетируемой переменной считается ИПЦ, а также показатель базовой инфляции, который рассчитывается как ИПЦ, скорректированный с учётом факторов, не подверженных влиянию ГДКП, таких как цены на продовольствие, на жильё и т.п., что согласуется с мировым опытом. [14] Индекс потребительских цен (ИПЦ) представляет собой отношение стоимости абстрактной потребительской корзины текущего периода к её стоимости за период, который взят в качестве базисного. Состав потребительской корзины регулируется Ф3-227 «О потребительской корзине в целом и по Российской Федерации».

Что качается горизонта таргетирования (периода, к концу которого цель должна быть достигнута), в нашей стране определяются плановый (от 1 до 3 лет) и операционный (1 год). По мнению авторов, одной из конечных целей Банка России при политике гибкого таргетирования должно стать определение и достижение также стратегического, или долгосрочного (более 3 лет) ориентира, т.к. внутри такого интервала возможен выбор между достижением операционной цели по инфляции и колебанием выпуска. [4]

Таким образом, проводимая на данный момент антиинфляционная политика может быть классифицирована как дефляционная.
Как следует из определения, первопричина инфляции заключается в возникновении диспропорций между различными сферами экономики (спросом и предложением и т.д.). К денежным факторам инфляции относят: дефицит гос.бюджета, неправильную политику доходов, увеличение скорости оборота денег, рост гос. долга и другие. Факторами неденежного характера считают: структурные диспропорции в общественном воспроизводстве, финансовую несбалансированность и монополизацию экономики.

На основании различного понимания экономическим школами инфляции выделяют два основных её вида - инфляцию спроса и инфляцию издержек. По формам проявления инфляция бывает открытой и подавленной, а в зависимости от роста цен - ползучей (до 10\% в год), галопирующей (100-200\%) и гиперинфляцией (более 50\% в месяц или более 1000\% в год). По показателю сбалансированности встречается сбалансированный уровень инфляции, при котором стоимость различных категорий товаров меняется в одинаковых пропорциях, и несбалансированной. По предсказуемости выделяют ожидаемую и неожиданную инфляцию. Отдельно выделяют явление стагфляции, что является одновременным повышением уровня цен, уменьшение производства в экономическом секторе и увеличение такого явления, как безработица.

В большинстве случаев инфляционные процессы действуют деструктивно на экономическую и социальную, общественные сферы. Однако при небольших темпах инфляция может оказывать и положительное влияние на экономику страны.

Что касается инфляционных процессов, происходящих в России, можно сказать, что для нашей страны характерна открытая, несбалансированная, подкреплённая инфляция, темп роста которой по данным на 2013 г., равен $6,8 \%$.

Как было сказано выше, инфляция- это многофакторный процесс, и это хорошо видно на примере экономики нашей страны. Так, на возникновение и обострение инфляционных процессов в России в основном оказывают влияние: господство монополий, в частности, связанных с добывающей промышленностью и поставкой газа, непропорциональное развитие экономической отрасли, что ведет к отставанию отраслей потребительского сектора и преувеличенного развития индустрии тяжелой промышленности, инициация инфляционных процессов непосредственно государством, высокие инфляционные ожидания субъектов экономики, девальвация российской национальной валюты.

Основной мерой по борьбе с инфляцией на современном этапе является недавний переход от политики 
монетарного таргетирования к инфляционному таргетированию, получившему распространение в большинстве стран с развитой экономикой.

Таким образом, инфляция - это сложный, многофакторный процесс, противоречиво влияющий на экономику, но являющийся неотъемлемой её частью и требующий дальнейшего тщательного изучения с целью достижения лучшей управляемости.

Уникальный характер российской инфляции требует использования особых методов ее регулирования, соответствующих современным реальным условиям хозяйствования. Антиинфляционная программа должна учитывать реальное развитие рыночных отношений, возможность использования рыночных механизмов с участием государственного регулирования.

Цель антиинфляционной политики государства состоит в том, чтобы установить контроль над инфляцией и добиться приемлемых для народного хозяйства темпов ее роста. Попытки справиться с инфляцией путем рестрикционной денежной политики в российских условиях имеют значительно более тяжелые последствия, чем сама инфляция, так как являются тормозом экономического роста, решения социальных задач.

Основным фактором в борьбе с инфляцией являются улучшение общей экономической ситуации в стране, повышение инвестиционной активности, формирование стабильной рыночной инфраструктуры. Сохранение темпов роста экономики на уровне 7-8\% требует расширения инвестиций и инноваций для модернизации всех отраслей промышленности, а не только в экспортных отраслях ТЭК. В связи с этим особое значение для экономики приобретает поддержка приоритетных отраслей народного хозяйства, стимулирование диверсификации экспорта продукции, разумная протекционистская политика и политика валютного курса, что будет способствовать повышению конкурентоспособности отечественных товаров.

Большое значение в антиинфляционной политике имеют структурная перестройка экономики и ее приспособление к потребностям рынка благодаря демонополизации и регулированию деятельности существующих монополий, стимулированию конкуренции в производстве, распределении, секторе услуг и т.д.

В сложившихся условиях решающим фактором борьбы с инфляцией будет возможность восстановления государственных структур управления и контроля за ценами и доходами, распределением и перераспределением материальных и финансовых ресурсов при проведении курса на преимущественное применение свободных рыночных цен. Вместе с тем сохраняется необходимость государственного регулирования цен на энергоносители, продукцию, выпускаемую монопольными структурами, транспортные услуги, услуг ЖКХ а также в процессе ликвидации «ножниц цен» на промышленную и сельскохозяйственную продукцию.

Блокировка финансовых факторов инфляции связана с решением проблемы собираемости налогов.

Особое внимание в антиинфляционной политике должно быть уделено совершенствованию налоговой системы:

- сокращению количества взимаемых налогов и их снижению;

- пересмотру налоговых платежей, включаемых в издержки производства, которые стимулируют рост цен - отчислений в пенсионный фонд, фонд социального страхования, фонд занятости населения, платы за землю, налога на имущество и т.д.;

- изменению методики налогообложения;

- регулированию перераспределительных отношений между бюджетами Федерации и бюджетами регионов.

Важным направлением в антиинфляционной политике являются дальнейшее развитие и государственное регулирование валютного и финансового рынков, а также совершенствование механизма формирования валютного курса.

Основой внешнеэкономической деятельности продолжают оставаться развитие экспорта и укрепление его базы, что требует обеспечения эффективного экспортного и валютного контроля с целью остановить «бегство» капитала за рубеж и обеспечить своевременность и полноту уплаты налогов по этим операциям. Экономика страны нуждается в программе возвращения российских капиталов, а также в привлечении иностранных капиталов для инвестиций. Этому может также способствовать восстановление доверия к банкам и правительству.

Предстоит нейтрализовать внешние факторы инфляции за счет использования налоговых пошлин и развития импортозаменяющих производств. Кроме этого, России предстоит преодолеть зависимость экономики, бюджета, валютного курса, ценообразования от внешних факторов, конъюнктуры мировых рынков.

Большое значение для сдерживания инфляции может иметь перестройка экспорта и импорта. Речь идет о переходе с сырьевой ориентации экспорта на технологические 
виды продукции, а также отказ от бросовых цен, по которым реализуется отечественное сырье и теряется экспортная выручка на десятки миллиардов долларов в год.

Одну из определяющих ролей в проведении антиинфляционной политики играет Центральный банк Российской Федерации, который осуществлял денежно-кредитное регулирование. Он должен ориентироваться не только на снижение инфляции, но и на более равновесное и стабильное развитие экономики, а также смягчить ограничения денежной массы в обращении и добиваться улучшения ее структуры, поскольку более высокие темпы роста менее ликвидных компонентов денежной массы приводят к ослаблению инфляционного давления, сокращение же объема наличных денег позволяет уменьшить темпы инфляции.

Необходимо прямое управление кредитной эмиссией, направленной на восстановление хозяйственных связей и банковской системы, подъем производства. Для сдерживания инфляции нужна поддержка инвестиционной активности коммерческих банков (хотя бы в рамках льгот по созданию обязательных резервов Банка России), как это принято в мировой практике.
Кредитование инвестиционной деятельности должно стать важнейшей стратегической задачей банков.

Важным фактором для борьбы с инфляцией имеет снятие инфляционных ожиданий как у хозяйствующих структур, так и у населения, что в значительной мере может быть обусловлено экономической и политической стабильностью в стране, более взвешенными выступлениями в средствах массовой информации.

Успешное осуществление антиинфляционной политики возможно только на основе разработки нормативных актов, регулирующих все сферы рыночных отношений и безусловного выполнения существующего законодательства.

В странах с развитой рыночной экономикой при регулировании инфляции монетаристские методы в чистом виде используются крайне редко; они, как правило, сочетаются с элементами других теорий: кейнсианской, концепцией «экономики предложений», «структурной инфляцией» посредством макроэкономического регулирования и структурной перестройки экономики, стимулирования производства товаров.

\section{ЛИТЕРАТУРА}

1. ЦЦ РФ: Основные направления единой государственной денежно-кредитной политики на 2019 год.

2. Деньги. Кредит. Банки / Белотелова Н.П.: учебник 4-е изд. - М.: 2017. - 400 с. (стр. 119-155)

3. Деньги. Кредит. Банки. /Жуков Е.Ф., Эриашвили Н.Д., Зеленкова Н.М. 4-е изд., перераб. и доп.— М.: 2018. — 783 с. (стр.278-279)

4. Макроэкономика. Теория. Практика. Безопасность [Электронный ресурс]:учебник/А.А. Анисимов, Н.В. Артемьев, О.Б. Тихонова; ред. Е.Н. Барикаев. М.: ЮНИТИ-ДАНА, 2019, 598 с. (стр. 235-270)

5. Деньги, кредит, банки./ Кузнецова Е.И. 2-е изд.— М.: 2019.— 568 с. (стр. 175-204)

6. Агеева Н.А. Таргетирование инфляции: сущность, инструменты, ожидаемый результат //Вестник Иркутского государственного технического университета. 2019. - № 2. - С. 183-188.

7. Дрючевский Д.В. Инфляция как экономический феномен с позиций различных школ и направлений экономической науки// Вестник Челябинского государственного университета. 2018. — № 19 (273). - С. 26-31.

8. Статистический анализ индекса потребительских цен Евгенова М.С., 2019// Студенческий научный форум scienceforum.ru

9. Ершов М.В., Татузов В.Ю., Урьева Е.Д. Инфляция и монетизация экономики //Деньги и кредит. 2020.— № 4. — С. 7-12.

10. Ермоленко 0.Д. Возможности перехода к таргетированию инфляции в России: факторы, его ограничивающие//Политематический сетевой электронный научный журнал Кубанского государственного аграрного университета. 2020.— № 75.— С. 643-652.

11. Колпакова И., Биляк С., Зедина Ю. Особенности инфляции и антиинфляционных мер в России: новая точка зрения в старой дискуссии// Вестник Института экономики РАН. 2019. — № 4.- - С. 111-127.

12. Коровин Е., Горская Е. Инфляция: прогноз благоприятный//Прямые инвестиции. 2019. — № 1 (129). — С. 74-75

13. Кузьмин 0. Природа российской инфляции не обязательно требует повышения ставок для борьбы с нею // Ведомости - 2018.

14. Приветкин А.А. Новый взгляд на сущность денег и инфляции Ежегодник «Виттевские чтения. 2018. — № 1. — С. 190-195.

15. Пищик В.Я. Мировой опыт таргетирования инфляции и возможности его использования в России// Этап: экономическая теория, анализ, практика. 2020. - № 3.- - . 62-78.

16. Рыбина С.С. Таргетирование инфляции: проблемы внедрения //Ежегодник Виттевские чтения. 2019. — № 1. — C. 99-100.

17. Рябых В.Н. К вопросу о перспективах регулирования инфляционных процессов в российской экономике. Часть 1. Причины инфляции и особенности инфляционного таргетирования как одной из приоритетных мер управления инфляцией// Вестник Тамбовского университета. Серия: Гуманитарные науки. 2019. - Т. 109.— № 5.— С. 124-133.

18. Савин А.В. Влияние инфляции на инновационное развитие Российской Федерации//ВестникУниверситета (Государственный университет управления). 2019. — № 11-1. — C. 54-57. 
19. Токаева Т.И. Инфляция и методы её регулирования//Terra Economicus. 2018. -Т. 11.— № 2-3.— C. 31-35.

20. Чаркин А.В. ВнедрениегибкоготаргетированияинфляциивРоссии//Научно-исследовательскийфинансовыйинститут.Финансовыйжурнал.2019.-№ 3.C. 73-88.

21. Экономическая статистика: report.ru

22. Информационный новостной портал: NEWSru.com

23. Новостной портал: vesti.ru

24. Интерфакс новости: interfax.ru

25. Сайт ЦБ: cbr.ru

26. Сайт федеральной службы госстатистики: http://www.gks.ru

○ Боробов Василий Николаевич ( vborobov@mail.ru ), Миндлин Юрий Борисович ( mindliny@mail.ru ).

Журнал «Современная наука: актуальные проблемы теории и практики»

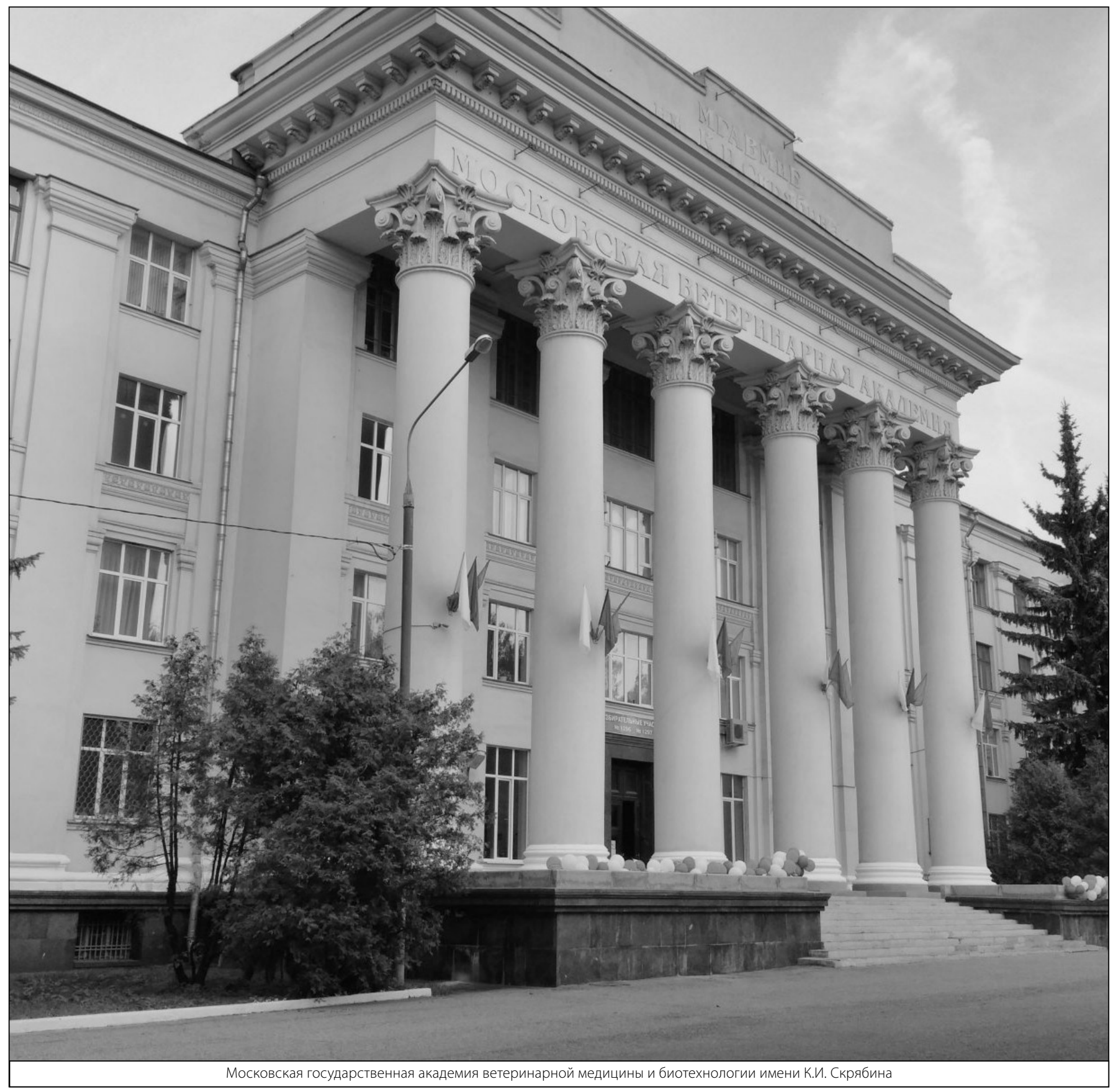

